\title{
Factors affecting deliveries attended by skilled birth attendants in Bangladesh
}

\author{
Gulam Muhammed Al Kibria ${ }^{\text {* }}$, Swagata Ghosh², Shakir Hossen', Rifath Ara Alam Barsha ${ }^{3}$, Atia Sharmeen ${ }^{4}$ \\ and S. M. Iftekhar Uddin'
}

\begin{abstract}
Background: The presence of skilled birth attendants (SBAs) is crucial in childbirth to reduce the maternal mortality ratio (MMR) and to achieve the maternal mortality target of the United Nations' Sustainable Development Goals (SDGs). The aim of this study was to investigate the factors related to childbirths attended by SBAs in Bangladesh.

Methods: Data from the Bangladesh Demographic and Health Survey (2014 BDHS) were analyzed. Logistic regression was applied to calculate crude odds ratios (CORs), adjusted odds ratios (AORs), 95\% confidence intervals (Cls), and p-values.

Results: In Bangladesh, 35.9\% of deliveries were attended by SBAs, and 44.2\% of those women received at least one antenatal check-up by a skilled provider. The deliveries by SBAs were less than $50 \%$ of the total deliveries in all divisions, excluding Khulna. Known pregnancy complications (AOR: 1.2; 95\% Cl: 1.1-1.4), higher level of education in both women (AOR: 1.7; 95\% Cl: 1.2-2.3) and their husbands (AOR: 1.8; 95\% Cl: 1.3-2.4), receiving antenatal care (ANC) by a skilled provider during the pregnancy period (AOR: 1.5; 95\% Cl: 1.1-2.1), and higher wealth quintiles (AOR: 3.4; 95\% Cl: 2.5-4.7) were all significantly associated with an increased likelihood of a delivery by SBAs $(p<0.05)$. In contrast, women living in rural areas (AOR: $0.7 ; 95 \% \mathrm{Cl}: 0.6-0.8)$ and the Sylhet Division (AOR: 0.4 ; $95 \% \mathrm{Cl}$ : $0.3-0.5$ ) were less likely to be delivered by SBAs.

Conclusions: To achieve the target of the Government of Bangladesh - 50\% of deliveries to be attended by SBAs - it is important to increase ANC services and awareness programs in all seven divisions of Bangladesh. Special focus in rural areas is also required to meet this target. A new study should be conducted to explore the unexamined factors associated with the presence of SBAs during childbirth.
\end{abstract}

Keywords: Maternal mortality ratio, Skilled birth attendants, Factors, Delivery, Childbirth, Bangladesh

\section{Plain english summary}

The maternal mortality ratio (MMR) is high in Bangladesh. The presence of skilled birth attendants (SBAs) during delivery may reduce this high MMR. To meet the MMR target of the United Nations' Sustainable Development Goals (SDGs) it is important to increase the number of deliveries attended by SBAs. This study was conducted to examine the factors associated with deliveries attended by SBAs.

Cross-sectional secondary, and generalizable data from the Bangladesh Demographic and Health Survey (2014

\footnotetext{
* Correspondence: drkibriacomc13@yahoo.com

'Department of International Health, Johns Hopkins Bloomberg School of

Public Health, 615 North Wolfe Street, Baltimore, MD 21205, USA

Full list of author information is available at the end of the article
}

BDHS) were analyzed. Factors were selected based on published reports and available data.

The factors that were found to be positively associated with deliveries attended by SBAs included known pregnancy complications higher education level of women, receiving antenatal care (ANC) by a skilled provider during the pregnancy period, and higher wealth quintile. Conversely, the factors that were inversely associated with deliveries attended by SBAs included living in rural areas and divisions other than Khulna.

A survey was recommended to investigate the associations of factors not explored in this study but that were validated in previous studies. The government should focus more on rural areas along with divisions with a low presence of SBAs during delivery. It was also 
recommended to focus on potential factors (e.g., ANC visit by a skilled provider and identifying pregnancy complications) to improve the number of deliveries attended by SBAs.

\section{Background}

Despite a substantial reduction of the estimated maternal mortality ratio (MMR) in Bangladesh from 550 per 100,000 live births in 1990 to 176 per 100,000 live births in 2015 the MMR is higher than most other countries [1]. Reduction of the MMR was a target of the United Nations' (UN) Millennium Development Goals (MDGs), and it is also stated as one of the Health Goals (Goal 3) of the UN's Sustainable Development Goals (SDGs) SDG 3.1 aims to reduce MMR to less than 70 per 100,000 live births by 2030 [2]. The estimated annual reduction of MMR in Bangladesh from 1990 to 2015 was $5 \%$ and to achieve the targets of the SDGs this progress needs to be accelerated [3].

According to the World Health Organization (WHO) skilled birth attendants (SBAs) are accredited health professionals (such as midwives, doctors, or nurses) who have been educated and trained to proficiently manage normal (i.e., uncomplicated) pregnancies, childbirths and the immediate postnatal period, as well as handle the identification, management and referral of complications in women and newborns [3]. The presence of SBAs can significantly reduce maternal and neonatal mortality by preventing or managing most obstetric complications $[4,5]$ including stillbirths [6]. In addition to the high MMR, Bangladesh has a high neonatal mortality rate with an estimated 23 per thousand live-births in 2015 [7].

The latest 2014 Bangladesh Demographic and Health Survey (2014 BDHS) revealed that the percentage of deliveries attended by SBAs in Bangladesh increased from $16 \%$ in 2004 to $42 \%$ in 2014 [8]. This rate is below the targeted level $(50 \%)$ of the Health Population and Nutrition Sector Development Program (HPNSDP) set by the Ministry of the Health and Family Welfare (MOHFW) of the Government of Bangladesh [9]. To increase the number of deliveries attended by SBAs in Bangladesh and to achieve the target of the HPNSDP, a clear, focused, and evidence-based approach is needed. The identification of the factors that affect deliveries attended by SBAs is important in this approach. There are few recent studies in Bangladesh that have examined the factors associated with the presence of SBAs during deliveries, which ultimately limits our understanding of this problem and indicates that this issue has been underestimated in Bangladesh. Therefore, further comprehensive studies are required.

Previous studies found that factors of different levels such as individual household or socioeconomic conditions simultaneously affect the decision of delivery attended by SBAs [10-14]. In Bangladesh, there is inequality in rural and urban areas, and inequality according to region and division. A population-based and nationally representative study may reveal the overall state of the SBA attended deliveries, which would be beneficial for the planning of health programs. It is better to address the modifiable factors and the areas or regions requiring intervention to increase the number of deliveries attended by SBAs. We attempted to identify and fill these existing gaps of knowledge to inform the policymakers and researchers to take a risk-specific intervention approach. We examined the factors that affect the decision of an SBA attended delivery by analyzing a nationally representative dataset from Bangladesh.

\section{Methods}

\section{Ethics statement}

We used anonymized survey data that were available for academic use ethical approval for this study was not required. We obtained approval to use the data from ICF International Rockville, Maryland, USA in August 2016.

\section{Data source}

We analyzed secondary and cross-sectional data from the 2014 BDHS. This survey was conducted from June to November 2014 by Mitra and Associates. Details of this population-based survey including survey design methodologies, findings, and questionnaires have been described elsewhere [8].

Three types of questionnaires were used in the 2014 BDHS: a household questionnaire a women's questionnaire, and a community questionnaire. Information from ever-married women aged 15-49 years was collected by the women's questionnaire. A total of 164 field workers were recruited based on experience, education level, and their willingness. Then, they were trained to conduct the oral interview [8].

Women were asked questions on the following topics: background characteristics (e.g. age, education, religion, media exposure), reproductive history, use and source of family planning methods, antenatal care, delivery care, postnatal care, newborn care, breastfeeding and infant feeding practices, child immunizations and illnesses, marriage, fertility preferences, husband's background and respondent's work, and awareness of AIDS and other sexually transmitted infections [8].

\section{Sample design}

To represent the demographics of women across the country the sample of the BDHS survey was nationally representative. The survey used a sampling frame from the list of enumeration areas (EAs) of the 2011 Population and Housing Census of the People's Republic of Bangladesh, provided by the Bangladesh Bureau of Statistics (BBS) [8]. 
The survey was based on a two-stage stratified sample of households. In the first stage 600 EAs were selected with a probability proportional to the EA size there were 207 EAs in urban areas and 393 in rural areas. A complete household listing operation was then carried out in all of the selected EAs to provide a sampling frame for the second-stage selection of households. In this second stage of sampling a systematic sample of 30 households on average was selected per EA the sample provided statistically reliable estimates of the key demographic and health variables for the country as a whole for urban and rural areas separately, and for each of the seven divisions. With this design, the survey selected 18,000 households with the expectation of approximately 18,000 completed interviews with ever-married women [8].

The weighted distribution of urban-rural households in the survey was based on the urban-rural distribution of the 2011 population census of the country a modified urban-rural household distribution was reflected by adjusting the sample weights and any significant differences in the overall survey indicators were not expected among the population [8].

\section{Coverage of the sample}

Initially 17,989 households were selected based on the weighting of the population distribution of rural-urban place and division. Among the selected households, 17,565 were occupied during the time of the interview, and $17,300(99 \%)$ of the households were then interviewed. A total of 18,245 ever-married women of reproductive age (15-49years) were identified in these households, and 17,863 women were interviewed (98\% response rate). Rural and urban areas had similar response rates [8].

\section{Participants}

We examined a cohort of women among those who participated in the BDHS we minimized recall bias by including the women who had given birth to at least one child within the last five years which resulted in 6,855 deliveries within this period. For our study, we considered one delivery per woman as a single unit of analysis. In addition, as some women delivered more than once in this 5-year period, we considered their latest delivery as the delivery to be included in the analysis. In this way, 4,468 women delivered at least one child within the previous 5 -year period and they were included in our analyses.

\section{Outcome}

Women reported on their last childbirth and stated whether attendants were present during their childbirth. In our analysis we used the WHO definition to incorporate deliveries attended by SBAs.
Using this definition, SBAs included qualified doctors, nurses, midwives, family welfare visitors, and community skilled birth attendants [4]. We defined traditional birth attendants, unqualified doctors, relatives, neighbors, and others as unskilled attendants.

We then coded the birth attendant variable according to the assistance of delivery (SBA $=1$ and unskilled attendant $=0$ ).

\section{Exposure variables}

We selected the following individual fertility and contextual factors based on published reports and data structure of the BDHS: age of the women and their husbands, parity, birth interval, previous history of deceased children, education level of the women and their husbands, occupation of the women, wealth quintile, exposure to mass media (i.e., radio, television or newspaper), receiving antenatal care (ANC) during pregnancy, division, place of residence (i.e., urban or rural), and religion.

\section{Statistical analyses}

A contingency table was used to describe the selected background characteristics and to compare women according to the selected characteristics. Simple and multiple logistic regression analyses were applied to calculate crude (unadjusted) odds ratios (CORs) and adjusted odds ratios (AORs) respectively. The odds ratios (ORs) with 95\% confidence intervals (CIs) and significance levels ( $p$-value) were reported. Only variables with a predetermined significance level $(p<0.2)$ in the simple logistic regression were kept in the multiple logistic regression. Variance inflation factors (VIFs) were estimated to check collinearity. High collinearity was assumed for a VIF greater than 10 .

The discrete variables (i.e. age, parity, birth interval, number of children) were converted into categorical variables. The wealth index groups were based on household assets and facilities. The ownership of assets (i.e., television, radio, fridge, car, bicycle, and motorcycle), and facilities (i.e., source of drinking water, type of toilet, electricity, and type of building materials used in the place of dwelling) were weighted using a principal component analysis (PCA). Stata 13.0 (Stata Corp, College Station, TX) was used for all data analyses.

\section{Results}

The selected background characteristics of the participants according to birth attendant' group (i.e. skilled or unskilled) are shown in Table 1. Among 4,468 of the women included in the study, $35.9 \%$ were attended by skilled attendants during childbirth. The majority of women were from the younger reproductive age group (54.9\%), followed by the middle (39.1\%) and late $(6.0 \%)$ 
Table 1 Percentage distribution of women according to birth attendants and selected background characteristics

\begin{tabular}{|c|c|c|c|}
\hline Characteristics & Unskilled BAs-N(\%) & SBAs-N(\%) ${ }^{a}$ & Total \\
\hline Total women & $2,864(64.1)$ & $1,604(35.9)$ & 4,468 \\
\hline \multicolumn{4}{|c|}{ Current age of women (years) } \\
\hline $15-24$ & $1,585(64.6)$ & $870(35.4)$ & 2,455 \\
\hline $25-34$ & $1,101(63.1)$ & $643(36.9)$ & 1,744 \\
\hline $35-49$ & $178(66.2)$ & $91(33.8)$ & 269 \\
\hline \multicolumn{4}{|c|}{ Husbands' age (years) } \\
\hline $15-25$ & $446(65.3)$ & $237(34.7)$ & 683 \\
\hline $25-40$ & $2,014(63.7)$ & $1,146(36.3)$ & 3,160 \\
\hline$>40$ & $404(64.6)$ & $221(35.4)$ & 625 \\
\hline \multicolumn{4}{|l|}{ Parity } \\
\hline 1 & $1,009(55.6)$ & $806(44.4)$ & 1,815 \\
\hline$\geq 2$ & $1,855(69.9)$ & $798(30.1)$ & 2,653 \\
\hline \multicolumn{4}{|c|}{ Birth Interval (years) } \\
\hline $0-2$ & $247(76.9)$ & $74(23.1)$ & 321 \\
\hline$\geq 3$ & $2,617(63.1)$ & $1,530(36.9)$ & 4,147 \\
\hline \multicolumn{4}{|c|}{ Pregnancy complications } \\
\hline No & $1,126(60.9)$ & $724(39.1)$ & 1,850 \\
\hline Yes & $874(53.0)$ & $776(47.0)$ & 1,650 \\
\hline Don't know & $864(89.3)$ & $104(10.7)$ & 968 \\
\hline \multicolumn{4}{|c|}{ Previous history of dead children } \\
\hline 0 & $2,437(62.5)$ & $1,464(37.5)$ & 3,901 \\
\hline 1 & $362(75.3)$ & $119(24.7)$ & 481 \\
\hline$\geq 2$ & $65(75.6)$ & $21(24.4)$ & 86 \\
\hline
\end{tabular}

Receiving at least one antenatal care by a skilled provider

$\begin{array}{llll}\text { No } & 1,043(86.8) & 159(13.2) & 1,202 \\ \text { Yes } & 1,821(55.8) & 1,445(44.2) & 3,266\end{array}$

Education level of women

$\begin{array}{ll}\text { No formal education } & 502(83.4) \\ \text { Primary } & 946(77.0) \\ \text { Secondary } & 1,259(59.5) \\ \text { Higher } & 157(30.1)\end{array}$

Education level of husbands of the women

$\begin{array}{llll}\text { No formal education } & 831(81.2) & 192(18.8) & 1,023 \\ \text { Primary } & 989(73.4) & 359(26.6) & 1,348 \\ \text { Secondary } & 808(57.4) & 599(42.6) & 1,407 \\ \text { Higher } & 335(34.2) & 453(65.8) & 688\end{array}$

Sex of the household head

$\begin{array}{llll}\text { Male } & 2,603(64.1) & 1,461(35.9) & 4,064 \\ \text { Female } & 261(64.6) & 143(35.4) & 404\end{array}$

Occupation of the women

$\begin{array}{ll}\text { Not working } & 2,184(62.5) \\ \text { Working } & 679(69.8)\end{array}$

Table 1 Percentage distribution of women according to birth attendants and selected background characteristics (Continued)

\begin{tabular}{llll}
\hline Wealth quintile & & & \\
Poorest & $802(85.7)$ & $134(34.3)$ & 936 \\
Poorer & $662(77.9)$ & $188(22.1)$ & 850 \\
Middle & $574(67.0)$ & $283(33.0)$ & 857 \\
Richer & $524(55.9)$ & $414(44.1)$ & 938 \\
Richest & $302(34.1)$ & $565(65.9)$ & 887
\end{tabular}

Frequency of reading newspaper

$\begin{array}{llll}\text { No } & 2,581(68.8) & 1,171(31.2) & 3,752 \\ \text { Less than once a week } & 194(46.7) & 221(53.3) & 415 \\ \text { At least once a week } & 81(27.9) & 209(72.1) & 290\end{array}$

Frequency of listening to radio

$\begin{array}{llll}\text { No } & 2,749(64.5) & 1,513(35.5) & 4,262 \\ \text { Less than once a week } & 45(50.0) & 45(50.0) & 90 \\ \text { At least once a week } & 70(60.3) & 46(39.7) & 116\end{array}$

Frequency of watching television

$\begin{array}{llll}\text { No } & 1,461(79.2) & 383(20.8) & 1,844 \\ \text { Less than once a week } & 275(70.0) & 118(30.0) & 393 \\ \text { At least once a week } & 1,128(50.6) & 1,103(49.4) & 2,231\end{array}$

Place of residence

$\begin{array}{llll}\text { Urban } & 692(48.1) & 747(51.9) & 1,439 \\ \text { Rural } & 2,172(71.7) & 857(28.3) & 3,029\end{array}$

Region (division)

\begin{tabular}{llll} 
Khulna & $250(47.6)$ & $275(52.4)$ & 525 \\
Barisal & $375(70.5)$ & $157(29.5)$ & 532 \\
Chittagong & $576(66.9)$ & $284(33.1)$ & 857 \\
Dhaka & $471(59.7)$ & $318(40.3)$ & 789 \\
Rajshahi & $334(61.3)$ & $211(38.7)$ & 545 \\
Rangpur & $353(65.0)$ & $190(35.0)$ & 543 \\
Sylhet & $508(75.0)$ & $169(25.0)$ & 677 \\
Religion & & & \\
Islam & $2,646(64.4)$ & $1,464(35.6)$ & 4,110 \\
Others & $218(60.9)$ & $140(39.1)$ & 358 \\
\hline Row percentage & & &
\end{tabular}

${ }^{a}$ Row percentage

reproductive age groups. There were $73.1 \%$ of women in our study who received ANC. Regarding education, 86.5\% of the women had formal education, whereas $77.1 \%$ of the husbands in the study had formal education. A vast majority of the women $(78.2 \%)$ were housewives and were not involved with any formal occupation. More than two-thirds of the women were from rural areas. A similar proportion of participants were obtained from each division. Less than one-tenth of the women were heads of household. There were $92.0 \%$ of the respondents who were Muslims.

The calculated crude and adjusted ORs of the selected variables with $95 \% \mathrm{CIs}$ and significance levels ( $p$-values) 
are presented in Table 2 . The variables with significance level up to 0.2 in the unadjusted level were included in the final adjustment to calculate the AORs. We did not find any specific variables to be highly collinear however there was a weak collinearity between ANC by a skilled health personnel and pregnancy complications, which had a VIF of 3.5.

The age group (of study women and their husbands) was not a significant predictor of the deliveries attended by SBAs $(p>0.05)$. The women with a gap of three or more years between subsequent deliveries were 1.5 times more likely to be delivered by SBAs compared to women with a birth interval of less than two years. The higher education level of women (AOR: 1.7 95\% CI: 1.2-2.3) and their husbands (AOR: 1.8 95\% CI: 1.3-2.4) was a significant predictor. The women from higher wealth quintiles were more likely to be delivered by SBAs in both the unadjusted (COR: 11.6 95\% CI: 8.9-15.1) and adjusted analyses (AOR: 3.4 95\% CI: 2.5-4.7). Though exposure to mass media (i.e. reading newspapers, listening to radio or watching television) was a significant predictor in the unadjusted level $(p<0.05)$, exposure to television did not remain significant after adjusting for other factors. The mothers who received a follow-up from an SBA during the pregnancy period increased the likelihood to be delivered by an SBA in comparison to the women who did not receive a follow up from an SBA (AOR: 1.5 95\% CI: 1.1-2.1). The likelihood of a delivery attended by SBAs was significantly lower in all six divisions compared to Khulna. Religion was not significantly associated with deliveries attended by SBAs.

\section{Discussion}

Our analyses revealed that known pregnancy complications higher education level of women, receiving ANC by a skilled provider during the pregnancy period, and higher wealth quintiles were positively associated with the deliveries attended by SBAs in Bangladesh. On the other hand, living in rural areas and divisions other than Khulna were inversely associated with the likelihood to be delivered by SBAs within the country. We did not find any association of deliveries attended by SBAs with age, history of child death, sex of the head of the household, exposure to mass media, and religion.

The education level of the husbands was positively associated with deliveries attended by SBAs in our study and this finding is supported by other studies [10-12]. This may be the result of greater knowledge and awareness of the importance of SBAs in deliveries. The association of education level may also be linked to the wealth quintile, as educated people have more opportunities to work and get well-paying jobs. Moreover, education was the strongest and most consistent predictor of health status [15]. As reported in other studies in Bangladesh, there was a significant association between women with an occupation outside of the home and deliveries by SBAs $[10,11]$. However, we found the opposite there was a negative association between women working outside of the home and deliveries attended by skilled attendants. A study in Nepal found a similar association [13].

Similar to other studies we found that women from higher wealth quintiles were more likely to be delivered by skilled attendants compared to less privileged women $[10,12,16,17]$. This may be due to the costs of SBAs during deliveries, which is difficult to manage for families with lower income. Improving the socio-economic status is difficult and a long-term process however a review of the BRAC-ICDDR,B Joint Research Project Working Paper Series in Bangladesh suggested that microcredit programs may improve maternal and child health conditions within the targeted program areas [18]. The application of improvement programs is a potential area for policymakers in the country to get involved.

We found that women living in rural areas were less likely to be delivered by SBAs. Mothers living in rural areas have less access to antenatal obstetric, and postnatal care services compared to their urban counterparts consequently women in rural areas do not utilize family planning, antenatal and other services as much as women in urban areas [8]. Less access and use of health services is closely linked to the lower socioeconomic conditions of rural people and inadequate health care services in rural areas of the country. In Bangladesh, there are vast differences between rural and urban utilization of health services there are also differences between rural and urban health-related outcomes including the neonatal and infant mortality rate and the maternal mortality ratio [8]. This inequality is required to be fulfilled by community-based programs. Moreover, more than $65 \%$ of the people of Bangladesh live in rural areas the people in rural areas should be prioritized to achieve desired health outcomes [19].

Women living in divisions other than Khulna were less likely to be delivered by SBAs. Moreover in all other divisions, less than one-third of the pregnant women were delivered by SBAs. Specifically, Sylhet had the lowest number of deliveries attended by SBAs in comparison to the other six divisions. Khulna is one of the best performing divisions for all health indicators in Bangladesh and was able to meet the governmental target for SBA attendance during childbirth compared to most of the other divisions Khulna had the highest proportion of women delivered in health facilities and the highest proportion of women receiving antenatal and postnatal care [8]. The differences in the regional use of health services contributed to the gap in health indicators and the increased number of deliveries attended by SBAs. The government should increase awareness 
Table 2 Logistic regression analyses showing the crude and adjusted odds ratios (with 95\% confidence intervals) and significance level, deliveries attended by skilled birth attendants in Bangladesh

\begin{tabular}{|c|c|c|c|c|}
\hline Characteristics & Crude OR (95\% Cl) & $p$-value & Adjusted OR(95\% Cl) & $p$-value \\
\hline \multicolumn{5}{|c|}{ Current age of women (years) } \\
\hline $15-24$ & Ref & & & \\
\hline $25-34$ & $1.1(0.9-1.2)$ & 0.3 & & \\
\hline $35-49$ & $0.9(0.7-1.2)$ & 0.6 & & \\
\hline \multicolumn{5}{|l|}{ Husbands' age (years) } \\
\hline $15-25$ & Ref & & & \\
\hline $25-40$ & $1.1(0.9-1.3)$ & 0.5 & & \\
\hline$>40$ & $1.0(0.8-1.3)$ & 0.8 & & \\
\hline \multicolumn{5}{|l|}{ Parity } \\
\hline 1 & Ref & & Ref & \\
\hline$\geq 2$ & $0.5(0.5-0.6)$ & $<0.001$ & $0.7(0.6-0.9)$ & $<0.001$ \\
\hline \multicolumn{5}{|l|}{ Birth interval (years) } \\
\hline $0-2$ & Ref & & Ref & \\
\hline$\geq 3$ & $1.9(1.4-2.6)$ & $<0.001$ & $1.3(0.9-1.8)$ & 0.1 \\
\hline \multicolumn{5}{|l|}{ Pregnancy complications } \\
\hline No & Ref & & Ref & \\
\hline Yes & $1.4(1.2-1.6)$ & $<0.001$ & $1.2(1.1-1.4)$ & $<0.05$ \\
\hline Don't know & $0.2(0.1-0.3)$ & $<0.001$ & $0.6(0.3-0.7)$ & $<0.05$ \\
\hline \multicolumn{5}{|c|}{ Previous history of dead children } \\
\hline 0 & Ref & & Ref & \\
\hline 1 & $0.5(0.4-0.7)$ & $<0.001$ & $0.9(0.8-1.3)$ & 0.9 \\
\hline$\geq 2$ & $0.5(0.3-0.9)$ & $<0.05$ & $1.5(0.8-2.6)$ & 0.2 \\
\hline \multicolumn{5}{|c|}{ Receiving at least one antenatal care by a skilled provider } \\
\hline No & Ref & & Ref & \\
\hline Yes & $5.2(4.1-6.6)$ & $<0.001$ & $1.5(1.1-2.1)$ & $<0.05$ \\
\hline \multicolumn{5}{|l|}{ Education level of women } \\
\hline No formal education & Ref & & Ref & \\
\hline Primary & $1.5(1.1-2.0)$ & $<0.001$ & $1.0(0.8-1.3)$ & 0.8 \\
\hline Secondary & $3.4(2.6-4.5)$ & $<0.001$ & $1.2(0.9-1.5)$ & 0.3 \\
\hline Higher & $11.6(8.4-16.0)$ & $<0.001$ & $1.7(1.2-2.3)$ & $<0.05$ \\
\hline \multicolumn{5}{|c|}{ Education level of husbands of the women } \\
\hline No formal education & Ref & & Ref & \\
\hline Primary & $1.6(1.3-1.9)$ & $<0.001$ & $1.3(0.9-1.4)$ & 0.3 \\
\hline Secondary & $3.2(2.6-3.9)$ & $<0.001$ & $1.3(1.0-1.6)$ & $<0.05$ \\
\hline Higher & $8.3(6.6-10.7)$ & $<0.001$ & $1.8(1.3-2.4)$ & $<0.001$ \\
\hline \multicolumn{5}{|c|}{ Sex of the household head } \\
\hline Male & Ref & & & \\
\hline Female & $1.0(0.8-1.2)$ & 0.8 & & \\
\hline \multicolumn{5}{|c|}{ Occupation of the women } \\
\hline Not working & Ref & & Ref & \\
\hline Working & $0.7(0.6-0.8)$ & $<0.001$ & $0.8(0.6-0.9)$ & $<0.001$ \\
\hline
\end{tabular}


Table 2 Logistic regression analyses showing the crude and adjusted odds ratios (with 95\% confidence intervals) and significance level, deliveries attended by skilled birth attendants in Bangladesh (Continued)

\begin{tabular}{|c|c|c|c|c|}
\hline \multicolumn{5}{|l|}{ Wealth quintile } \\
\hline Poorest & Ref & & Ref & \\
\hline Poorer & $1.7(1.3-2.3)$ & $<0.001$ & $1.3(1.0-1.7)$ & $<0.05$ \\
\hline Middle & $2.9(2.2-3.6)$ & $<0.001$ & $1.7(1.3-2.3)$ & $<0.001$ \\
\hline Richer & $4.7(3.6-6.1)$ & $<0.001$ & $2.2(1.6-2.8)$ & $<0.001$ \\
\hline Richest & $11.6(8.9-15.1)$ & $<0.001$ & $3.4(2.5-4.7)$ & $<0.001$ \\
\hline \multicolumn{5}{|c|}{ Frequency of reading newspaper } \\
\hline No & Ref & & Ref & \\
\hline Less than once a week & $2.5(2.0-3.0)$ & $<0.001$ & $1.2(0.9-1.5)$ & 0.1 \\
\hline At least once a week & $5.7(4.3-7.5)$ & $<0.001$ & $1.6(1.2-2.2)$ & $<0.05$ \\
\hline \multicolumn{5}{|c|}{ Frequency of listening to radio } \\
\hline No & Ref & & Ref & \\
\hline Less than once a week & $1.8(1.2-2.7)$ & $<0.05$ & $1.2(0.8-1.9)$ & 0.4 \\
\hline At least once a week & $1.2(0.8-1.8)$ & 0.3 & $0.6(0.4-1.0)$ & $<0.05$ \\
\hline \multicolumn{5}{|c|}{ Frequency of watching television } \\
\hline No & Ref & & Ref & \\
\hline Less than once a week & $1.6(1.3-2.1)$ & $<0.001$ & $1.0(0.8-1.3)$ & 0.8 \\
\hline At least once a week & $3.7(3.2-4.3)$ & $<0.001$ & $1.2(0.9-1.4)$ & 0.1 \\
\hline \multicolumn{5}{|l|}{ Place of residence } \\
\hline Urban & Ref & & Ref & \\
\hline Rural & $0.3(0.3-0.4)$ & $<0.001$ & $0.7(0.6-0.8)$ & $<0.001$ \\
\hline \multicolumn{5}{|l|}{ Region (division) } \\
\hline Khulna & Ref & & Ref & \\
\hline Barisal & $0.3(0.3-0.5)$ & $<0.001$ & $0.4(0.3-0.6)$ & $<0.001$ \\
\hline Chittagong & $0.4(0.4-0.6)$ & $<0.001$ & $0.4(0.3-0.5)$ & $<0.001$ \\
\hline Dhaka & $0.6(0.5-0.8)$ & $<0.001$ & $0.4(0.4-0.6)$ & $<0.001$ \\
\hline Rajshahi & $0.6(0.4-0.7)$ & $<0.001$ & $0.6(0.5-0.8)$ & $<0.001$ \\
\hline Rangpur & $0.5(0.4-0.6)$ & $<0.001$ & $0.5(0.4-0.7)$ & $<0.001$ \\
\hline Sylhet & $0.3(0.2-0.3)$ & $<0.001$ & $0.4(0.3-0.5)$ & $<0.001$ \\
\hline \multicolumn{5}{|l|}{ Religion } \\
\hline Islam & Ref & & Ref & \\
\hline Others & $1.1(0.9-1.4)$ & 0.2 & $1.1(0.8-1.4)$ & 0.6 \\
\hline
\end{tabular}

programs in the other six divisions and intervene to increase the likelihood of being delivered by SBAs.

Receiving ANC by a skilled health care provider during pregnancy and prolonged intervals between subsequent births were positively associated with deliveries attended by SBAs and this is corroborated by the findings from other studies of Bangladesh [10-12, 14]. A prolonged birth interval is also associated with increased awareness among women. Receiving counseling and information from the SBAs during pregnancy may increase the likelihood of being delivered by SBAs [20, 21] the pregnancy period is the most suitable opportunity for intervention. Moreover antenatal counseling is one of the four pillars of the Safe Motherhood Initiative based on its effectiveness [22].

A study in Nepal found an association between the autonomy of women and deliveries attended by SBAs [23]. However we did not find any association between head of household and deliveries attended by SBAs.

We considered that women who have been exposed to mass media (i.e. radio, television, and newspaper) were more likely to use SBAs during delivery. A study in Uganda found an association between exposure to mass media and birth preparedness [24] therefore we considered that women may become more aware of SBAs by advertisements or exposure to awareness 
programs. Moreover, one study in Bangladesh found a positive association between the use of contraceptives and television exposure [25]. Television exposure appeared to be a significant predictor in the calculated CORs however television exposure did not remain significant when we adjusted for other factors. This suggests that women were either not informed of a delivery by SBAs due to the absence of awareness programs or if exposed, women were reluctant to adopt it. We were unable to investigate whether women were exposed to an awareness program through mass media due to unavailable data.

One limitation of our study is that we were unable to examine certain factors that were revealed in other studies. Several studies found the following associations with deliveries attended by SBAs: complications related to delivery distance to the nearest hospital, transportation issues to reach health facilities, presence of SBAs in the geographic area, and cost of SBAs [10-12, 16, 26-30]. These factors were also validated by studies in other countries [31-33]. We were unable to examine these factors due to unavailable data. Another limitation of this study is that we only analyzed the data of women who survived, and we were unable to investigate the determinants of the most affected group. The data were collected retrospectively, and the data were cross-sectional. Causality cannot be established fully as the condition may have changed after childbirth.

The main strength of this study is that the analysis is generalizable for Bangladesh as there was a large sample size accounting for the population across the entire country. To our knowledge, no other studies in Bangladesh were able to identify the divisions with fewer deliveries attended by SBAs. The response rate of the survey was high (approximately 99\%), and there was little missing data. Furthermore, the possibility of a recall bias was minimized by interviewing only women with a history of childbirth within the last five years.

\section{Conclusions}

The analysis of the 2014 BDHS data revealed that individual, fertility, and contextual variables had a significant effect on the number of deliveries attended by SBAs. A delivery by skilled personnel is required for all women in Bangladesh regardless of age, location or socioeconomic condition. From a program planning perspective, to achieve the maternal mortality target of the United Nations' Sustainable Development Goals (SDGs) and to achieve the target of $50 \%$ of deliveries attended by SBAs of the Government of Bangladesh, it is important to consider the modifiable factors that affect the presence of SBAs during childbirth. To increase the number of deliveries attended by SBAs at the population level, community-based programs should focus on the positive factors such as ANC visits by a skilled provider and surveillance for complications during pregnancy; based on priority, health programs should include these components to increase awareness in rural areas and the divisions with a lower presence of SBAs during childbirth. Effective collaboration with stakeholders should be ensured, and further studies should be conducted to reveal unexamined factors associated with the presence of SBAs during childbirth.

\section{Abbreviations \\ ANC: Antenatal care; AOR: Adjusted odds ratio (AOR); BBS: Bangladesh Bureau of Statistics; BDHS: Bangladesh Demographic and Health Survey; Cl: Confidence interval; COR: Crude odds ratio (COR); EA: Enumeration areas; HPNSDP: Health, population and nutrition sector development program; MDGs: Millennium development goals; MMR: Maternal mortality ratio; MOHFW: Ministry of Health and Family Welfare; OR: Odds ratio; SBA: Skilled birth attendant; SDGs: Sustainable development goals; WHO: World Health Organization}

\section{Acknowledgments}

We would like to thank the ICF International, Rockville, Maryland, USA for giving us the permission to use the data for this study.

\section{Funding}

Not applicable for this study.

Availability of data and materials

Data may be made available upon request to the ICF International, Maryland, USA.

\section{Authors' contributions \\ GMAK and SH conceptualized the study, AS did literature review, GMAK and SG prepared the first draft of the manuscript, AS and RAAB performed statistical analyses, and IU did critical review of the manuscript. All authors read and approved the final manuscript.}

\section{Authors' information}

No additional information to disclose.

\section{Competing interests}

The authors declare that they have no competing interests.

\section{Consent for publication}

Not applicable for this study.

Ethics approval and consent to participate

Not applicable for this study.

\section{Publisher's Note}

Springer Nature remains neutral with regard to jurisdictional claims in published maps and institutional affiliations.

\section{Author details}

'Department of International Health, Johns Hopkins Bloomberg School of Public Health, 615 North Wolfe Street, Baltimore, MD 21205, USA. ${ }^{2}$ School of Public Health, University of Saskatchewan, Saskatoon, Saskatchewan, Canada. ${ }^{3}$ Department of Pediatrics, Sylhet M. A. G. Osmani Medical College Hospital, ProjAHNMo- Johns Hopkins University-Bangladesh, Sylhet, Bangladesh. ${ }^{4}$ Shimantik, Sylhet, Bangladesh.

Received: 23 September 2016 Accepted: 4 March 2017

Published online: 21 March 2017

\section{References}

1. WHO, UNICEF, UNFPA, World Bank Group and the United Nations Population Division. Trends in maternal mortality: 1990 to 2015. 2015;WHO/ RHR/15.23.

2. United Nations. Sustainable Development Goals. [http://www.un.org/ sustainabledevelopment/health/] 
3. World Health Organization, UNICEF. Trends in maternal mortality: 1990 to 2013: estimates by WHO, UNICEF, UNFPA, the world bank and the united nations population division: executive summary. 2014.

4. World Health Organization. Skilled Birth Attendants. [http://www.who.int/ maternal_child_adolescent/topics/maternal/skilled_birth/en/.]

5. Graham WJ, Bell JS, Bullough CH, De Brouwere V, Van Lerberghe W. Can skilled attendance at delivery reduce maternal mortality in developing countries, Safe motherhood strategies: a review of the evidence. 2001. p. 97-130.

6. Yakoob MY, Ali MA, Ali MU, et al. The effect of providing skilled birth attendance and emergency obstetric care in preventing stillbirths. BMC Public Health. 2011;11(3):1.

7. UN Inter-agency Group for Child Mortality. Child mortality estimates september 2015. 2015.

8. National Institute of Population and Research (NIPORT). Mitra and associates, ICF international. Bangladesh demographic and health survey 2014. 2016 [https://dhsprogram.com/pubs/pdf/FR311/FR311.pdf].

9. Ministry of Health and Family Welfare. Health, population and nutrition sector development program(HPNSDP). 1st ed. Dhaka, Bangladesh: Government of the People's Republic of Bangladesh; 2011.

10. Islam MA, Chowdhury Rl, Akhter HH. Complications during pregnancy, delivery, and postnatal stages and place of delivery in rural Bangladesh. Health Care Women Int. 2006;27(9):807-21. doi: T11172M0VM022K35 [pii].

11. Islam N, Islam MT, Yoshimura Y. Practices and determinants of delivery by skilled birth attendants in Bangladesh. Reprod Health. 2014;11:86-4755-1186. doi: 10.1186/1742-4755-11-86 [doi].

12. Chowdhury RI, Islam MA, Gulshan J, Chakraborty N. Delivery complications and healthcare-seeking behaviour: the Bangladesh demographic health survey, 1999-2000. Health Soc Care Community. 2007;15(3):254-64. doi: HSC681 [pii].

13. Dhakal S, van Teijlingen E, Raja EA, Dhakal KB. Skilled care at birth among rural women in Nepal: practice and challenges. J Health Popul Nutr. 2011; 29(4):371-8.

14. Rahman M. Deliveries among adolescent mothers in rural Bangladesh: who provides assistance? World Health Popul. 2009;11(2):5-14.

15. Bloomberg L, Meyers J, Braverman MT. The importance of social interaction: a new perspective on social epidemiology, social risk factors, and health. Health Educ Behav. 1994;21(4):447-63.

16. Koenig MA, Jamil K, Streatfield PK, et al. Maternal health and care-seeking behavior in Bangladesh: findings from a national survey. Int Fam Plan Perspect. 2007:33(2):75-82. doi: 3307507 [pii].

17. Zere E, Suehiro Y, Arifeen A, Moonesinghe L, Chanda SK, Kirigia JM. Equity in reproductive and maternal health services in Bangladesh. Int J Equity Health. 2013;12(1):1.

18. Sarkar M, Haider M. The case for microcredit: does It improve maternal and child health and wellbeing? Int J Public Health Sci (IJPHS). 2014;3(2):107-16.

19. Bangladesh Bureau of Statistics. Bangladesh population and housing census. 2011.

20. Palaniappan B. Role of antenatal care in safe motherhood. J Indian Med Assoc. 1995;93(2):53-4. 52

21. Sai FT, Measham DM. Safe motherhood initiative: getting our priorities straight. Lancet. 1992;339(8791):478-80.

22. World Health Organization. Mother-baby package: implementing safe motherhood in countries. In: Practical guide. 1st ed. Geneva: World Health Organization; 1996

23. Situ K, Neupane S. Women's Autonomy and Skilled Attendance During Pregnancy and Delivery in Nepal. Matern Child Health J. 2016:1-8.

24. Asp G, Pettersson KO, Sandberg J, Kabakyenga J, Agardh A. Associations between mass media exposure and birth preparedness among women in southwestern Uganda: a community-based survey. Global Health Action. 2014;7.

25. Goni A, Rahman M. The impact of education and media on contraceptive use in Bangladesh: a multivariate analysis. Int J Nurs Pract. 2012;18(6):565-73. doi:10.1111/ijn.12013.

26. Keya KT, Rob U, Rahman M, Bajracharya A, Bellows B. Distance, transportation cost, and mode of transport in the utilization of facility-based maternity services: evidence from rural Bangladesh. Int Q Community Health Educ. 2014;35(1):37-51. doi:10.2190/IQ.35.1.d.

27. Bari W, Chowdhury RI, Islam MA, Chakraborty N, Akhter HA. The differentials and determinants of perinatal mortality in rural Bangladesh. Eur J Contracept Reprod Health Care. 2002;7(4):216-22.
28. Barnett S, Azad K, Barua S, et al. Maternal and newborn-care practices during pregnancy, childbirth, and the postnatal period: a comparison in three rural districts in Bangladesh. J Health Popul Nutr. 2006;24(4):394-402.

29. Hajizadeh M, Alam N, Nandi A. Social inequalities in the utilization of maternal care in Bangladesh: Have they widened or narrowed in recent years?. Int J Equity Health. 2014;13:120-014-0120-4. doi: 10.1186/s12939-014-0120-4 [doi].

30. Hoque ME, Dasgupta SK, Naznin E, Al Mamun A. Household coping strategies for delivery and related healthcare cost: findings from rural Bangladesh. Trop Med Int Health. 2015;20(10):1368-75. doi:10.1111/tmi.12546.

31. Mayhew $\mathrm{M}$, Hansen PM, Peters $\mathrm{DH}$, et al. Determinants of skilled birth attendant utilization in Afghanistan: a cross-sectional study. Am J Public Health. 2008;98(10):1849-56. doi:10.2105/AJPH.2007.123471.

32. Yanagisawa $S$, Oum S, Wakai S. Determinants of skilled birth attendance in rural Cambodia. Trop Med Int Health. 2006;11(2):238-51. doi: TMI1547 [pii].

33. Ghosh S, Siddiqui MZ, Barik A, Bhaumik S. Determinants of skilled delivery assistance in a rural population: findings from an HDSS site of rural west Bengal, India. Matern Child Health J. 2015;19(11):2470-9. doi:10.1007/s10995-015-1768-0.

\section{Submit your next manuscript to BioMed Central and we will help you at every step:}

- We accept pre-submission inquiries

- Our selector tool helps you to find the most relevant journal

- We provide round the clock customer support

- Convenient online submission

- Thorough peer review

- Inclusion in PubMed and all major indexing services

- Maximum visibility for your research

Submit your manuscript at www.biomedcentral.com/submit 